\title{
Colour vision screening among Saudi Arabian children
}

\author{
O Matthew Oriowo* and Abdullah Z Alotaibi^^
}

Department of Optometry, College of Applied Medical Sciences, King Saud University, PO Box 10219, Riyadh 11433, Saudi Arabia

Received 29 April 2008; revised version accepted 30 June 2008

\begin{abstract}
Purpose: To determine the prevalence of congenital red-green colour vision defects among Saudi Arabian male and female children.

Methods: The study involved 1638 elementary and high school participants ( 838 males, and 800 females), who were randomly selected and screened for red-green colour vision defects using the Ishihara (pseudo-isochromatic plates) test. Inclusion criteria were Snellen VA 20/20 or better and absence of known ocular pathologies.
\end{abstract}

Results: Out of the 838 male participants, $5.85 \%$ demonstrated red-green colour vision deficiency (CVD), with $1.55 \%$ and $4.3 \%$ of the 49 males exhibiting protan and deutan defects, respectively.
Among the females, $0.75 \%$ of the 800 participants showed CVD, with $0.25 \%$ and $0.5 \%$ demonstrating protan and deutan defects, respectively.

Conclusion: The results show that the prevalence of red-green colour deficiency among the female children from central Saudi Arabia is not significantly different from that of female populations in western countries. The current prevalence among the males is higher than previously reported for central Saudi Arabia, but less than for Caucasian populations.

Keywords: Colour vision deficiency, Ishihara colour test, Prevalence, Red-green defects, Screening, Saudi Arabia.

\section{Introduction}

Congenital colour vision deficiency (CVD) is an X chromosome-linked recessive, autosomal dominant and very rarely autosomal recessive inherited trait $^{1-5}$. The genes responsible for red-green CVD are located on the long arm of the X-chromosome within the Xq28 band, 2, 6, 7 while the blue pigment gene resides on the 7 th chromosome ${ }^{2,3,8}$. A recent in-depth comparative review ${ }^{9}$ on fundamentals of colour vision indicates some non-primate retinas may have as many as five different cone types but most mammals only have two cone types, usually green- and blue- sensitive cones with their retinas containing predominantly rod photoreceptors ${ }^{10}$. However, humans and other old World primates are believed to be trichromatic and have similar colour sensation ${ }^{11}$. At present trichromatism is the generally accepted colour model where, red-, green- and blue-sensitive cones are involved in normal colour vision ${ }^{9,11}$.

Clinically, depending on the deficient or absent cone pigments, CVD may be classified into protan (red), deutan (green) and tritan (blue-yellow) types. The protan defects include a dichromatic form - protanopia, and a trichromatic form - protanomalous trichromacy. Colour awareness of protanopes and pro-

* BSc (Hons) Optom, MSc, PhD, FAAO

$\wedge$ BScOptom, MSc, PhD 
tanomalous trichromats is often qualitatively similar, justifying the inclusive term "protan". Similarly, the deutan defects include a dichromatic form - deuteranopia, and a trichromatic form - deuteranomalous trichromacy. Also the colour awareness of deuteranopes and deuteranomalous trichromats is usually similar, justifying the term "deutan" 5 . The tritan CVD type, a rare autosomal dominant trait has a prevalence of 1 in 15000 to 1 in 50000 (that is, $0.002-0.007 \%$ ) of the population $^{5,12}$. The complete achromatopsia or rod monochromacy, another type of congenital CVD, is a rare, autosomal recessive trait characterised by loss of function of all cone classes, severe photophobia, nystagmus, reduced visual acuity, and a total inability to discriminate colours. It occurs in about 0.003 percent of the population ${ }^{3,13}$.

The red-green type is the commonest of all types of CVD, and has a high prevalence in Caucasian populations, usually stated as being $8 \%$ of males and $0.4 \%$ females. It is known to have lower prevalence in nonCaucasian populations, notably among those that are still or until recently were farmer and/or hunter-gather societies ${ }^{14,16}$. Two previous studies ${ }^{16,17}$ have found a low prevalence of CVD among Arabs males living in Saudi Arabia, while one study in Iraq ${ }^{18}$ found a prevalence approaching that cited for Caucasian populations for Arabs living in Iraq as did another study for a sample of predominantly Arab Jordanians. ${ }^{19}$ The first colour vision study in Saudi Arabia ${ }^{16}$ found a geographical variation in prevalence among Arab males in Saudi Arabia, obtaining a prevalence of $2.3 \%$ for central region compared to $5.2 \%$ in the Eastern coastal region, and 5.7\% in the Southern region of Saudi Arabia. The second study ${ }^{17}$ found a slightly high prevalence of $2.93 \%$ among 11 to 18 year-old Saudi males from the central Saudi region. Post ${ }^{20}$ suggested that the high prevalence of CVD in industrialised societies is the evidence of rapid natural selection relaxation. However, it is controversial that photopigments are not subject to short term "natural selection" as suggested by Post ${ }^{20}$, and according to the Hardy-Weinberg equilibrium, since CVD is not a fatal disease, the prevalence should remain constant in a randomly mating population. The two previous studies in Saudi Arabia have focused on males, without information regarding the female population. Hence, the present study was conducted to determine the prevalence of CVD among female children, and compare the current male prevalence to previous findings in a care- fully selected sample of Central Saudi Arabian school children whose parents were born in Saudi Arabia.

\section{Methods}

The cross-sectional screening to determine the prevalence of red-green CVD among school age children from central Saudi Arabia was conducted during the months of June through December 2005. The study followed the tenets of the Helsinki Declaration, and approval for the study was obtained from the Faculty Research Committee, King Saud University, Riyadh. Judging from a documented population of elementary and secondary (3 year intermediate [i.e. junior secondary], and 3 year senior secondary) school students in the Riyadh municipal area being 399553 , and a reported average prevalence of $2.6 \%$ from previous studies in Saudi Arabia, a two-stage random sampling approach was employed to select a sample size of 2000 participants including males and females. Riyadh city area has a population of approximately 5 million people. The first stage of randomisation, involved obtaining the number of schools and students from the internet, and using the available list of schools obtained from the local inspectorate of education office of the Riyadh municipal area, to determine the number of schools required. This indicated the random selection of eight elementary (primary) schools and six secondary (3 intermediate / junior high; and 3 high) schools. In the second randomisation process, students to be screened were selected by balloting using the class register. One hundred pupils were selected from each elementary school and 200 students from each secondary school.

Information obtained from participants included name, date of examination, name of school, age, gender, and grade. A Snellen VA chart was placed at 6 meters in an assigned classroom with adequate daylight illumination, and VA was tested for all study participants, separately for each eye. Near VA was also assessed in both eyes. The students with or without correction that failed to read the 20/30 line at far and near on the VA charts were excluded. The students born to parents who are not from Saudi Arabia were excluded. Subjects with any evidence of ocular pathology, trauma, previous ocular surgery, amblyopia, or long-term use of medication were excluded. The spherical equivalent of the participants with ametropia corrected ranged between $+1.25 \mathrm{D}$ and $-3.50 \mathrm{D}$. 
The Ishihara (1997 edition) pseudo-isochromatic plates were utilised to test colour vision of all the participants. One of the peculiarities of red-green deficiencies is that blue and yellow colours appear to be clear compared with red and green colours ${ }^{21}$. The Ishihara colour test is an internationally accepted method for screening red-green colour vision deficiency by several authors $7,14,15,17,22$. The test was carried out in a room with sufficient indirect daylight. The light source in the testing room was a battery of $40 \mathrm{~W}$ Phillips (Daylight Deluxe 55) fluorescent lamps with colour rendering indices greater than 92, yielding approximate illumination of 280 lux, measured with a lux meter at the level of test surface (a distance of $50-75 \mathrm{~cm}$ from the subject). A minimum illumination source of 280 lux has been recommended to be adequate for valid interpretation of color test results ${ }^{23}$.

The Ishihara colour plates were held $75 \mathrm{~cm}$ from the subject and tilted so that the plane of the page is at right angles to subject's line of vision. All the testing was conducted under binocular viewing conditions. Each subject was asked to read the numbers on the first 14 plates of the test booklet, at 4 seconds per plate. The test was performed twice for all subjects. A subject who made more than three errors between plates 1 and 14 during first and/or second test session was judged to have failed the screening. Every subject considered to have failed the test was retested the third time. Each subject was considered having CVD if they had more than 3 errors at 2 out of 3 sessions. Such subject was then shown the Ishihara diagnostic plates (16 and 17) to determine if the CVD was protan or deutan type. The answers given by the subjects for each plate were recorded in a special study form which contains information like age, code number, sex, and type of red-green deficiency (if observed). The data were then analysed, and the CVD cases were classified as protan and deutan types.

\section{Results}

A total of 1638 participants including 838 males and 800 females, with age range from 6 to 19 years, completed the study. Forty-nine $(5.85 \%)$ of the 838 males, and $6(0.75 \%)$ of the 800 females, were found to have congenital red-green CVD in the present study. Of the $0.75 \%$ from the 800 female participants found to show red-green defects (Table 1), protans and deutans made up $0.25 \%$ and $0.5 \%$, respectively. Hence the protan to deutan ratio among females is 0.50 (1:2). In males, of the $5.85 \%$ from the 838 subjects found to have red-green defects, protans and deutans made up $1.55 \%$ and $4.3 \%$, respectively, (Table 1), hence the protan to deutan ratio is $0.36(1: 3)$. The $95 \%$ confidence interval (CI) was calculated using the CI proportion calculator provided by Dimension Research Inc. ${ }^{24}$ The comparisons between the results obtained in the present study and those previously reported in literature are shown in Table 2.

Table 1. The percentage of phenotypic frequency of the different types of red-green colour vision deficiency (CVD) among the participants $(\mathrm{n}=$ sample size $)$.

\begin{tabular}{|c|c|c|c|c|}
\hline \multirow{3}{*}{ Types of CVD } & \multicolumn{4}{|c|}{ Prevalence \pm SD } \\
\hline & \multicolumn{2}{|c|}{ Females $(n=800)$} & \multicolumn{2}{|c|}{ Males $(n=838)$} \\
\hline & $\mathrm{n}$ & $\%$ & $\mathrm{n}$ & $\%$ \\
\hline Protans & 2 & $0.25 \pm 0.35$ & 13 & $1.55 \pm 0.84$ \\
\hline Deutans & 4 & $0.50 \pm 0.49$ & 36 & $4.30 \pm 1.37$ \\
\hline $\begin{array}{l}\text { Red-Green } \\
\text { CVD (Total) }\end{array}$ & 6 & $0.75 \pm 0.84$ & 49 & $5.85 \pm 1.59$ \\
\hline
\end{tabular}


Table 2. Comparison of the present study results (prevalence \%) with samples of previous studies from different populations of certain countries.

\begin{tabular}{|c|c|c|c|c|c|c|}
\hline \multirow{2}{*}{$\begin{array}{l}\text { Country of } \\
\text { Study }\end{array}$} & \multirow[t]{2}{*}{ Population } & \multirow{2}{*}{$\begin{array}{c}\mathrm{N} \\
\mathrm{M} / \mathrm{F}\end{array}$} & \multirow{2}{*}{$\begin{array}{l}\text { Age } \\
\text { (yrs) }\end{array}$} & \multicolumn{2}{|c|}{ Prevalence $(95 \% \mathrm{CI})$} & \multirow[t]{2}{*}{ References } \\
\hline & & & & $\mathrm{M}$ & $\mathrm{F}$ & \\
\hline Denmark & Danish & $173 / 186$ & $\mathrm{~N} / \mathrm{A}$ & $8.67(4.48-12.86)$ & $0.54(0-1.59)$ & Norn $^{7}$ \\
\hline Greenland & Inuit & $290 / 250$ & $\mathrm{~N} / \mathrm{A}$ & $1.0(0-2.19)$ & $0.4(0.3-1.18)$ & Norn $^{7}$ \\
\hline Ethiopia & Ethiopians & $954 / 1054$ & $8-24$ & $4.20(2.93-5.47)$ & $0.2(0-0.45)$ & Zein $^{27}$ \\
\hline Italy & Caucasians & 3285 & $13-20$ & $6.10(5.28-6.92)$ & $\mathrm{N} / \mathrm{A}$ & Malaspina et $a l^{30}$ \\
\hline Iraq & Arabs & $1221 / 845$ & $\mathrm{~N} / \mathrm{A}$ & $8.19(6.66-9.74)$ & $3.2(2.01-4.39)$ & Al-Amood et al ${ }^{18}$ \\
\hline Iran & Iranians & $1136 / 922$ & $12-14$ & 8.18 & 0.43 & Modarres et $a l^{26}$ \\
\hline Jordan & Jordanians & $1200 / 218$ & $18-27$ & $8.72(4.97-12.47)$ & $0.33(0.01-0.65)$ & $\begin{array}{l}\text { Al-Aqtum \& Al- } \\
\text { Qawasmeh }\end{array}$ \\
\hline New Zealand & Caucasians & 817 & $\mathrm{~N} / \mathrm{A}$ & $6.50(4.81-8.19)$ & $\mathrm{N} / \mathrm{A}$ & Grosvenor $^{22}$ \\
\hline New Zealand & Polynesians & 571 & $\mathrm{~N} / \mathrm{A}$ & $2.60(1.29-3.91)$ & $\mathrm{N} / \mathrm{A}$ & Grosvenor $^{22}$ \\
\hline Pakistan & Punjabi & 214 & $\mathrm{~N} / \mathrm{A}$ & $4.89(0.00-0.00)$ & $\mathrm{N} / \mathrm{A}$ & Mian et $a l^{29}$ \\
\hline Saudi Arabia & Arabs & 133 & $\mathrm{~N} / \mathrm{A}$ & $2.30(0.25-4.85)$ & $\mathrm{N} / \mathrm{A}$ & Voke $\&$ Voke $^{16}$ \\
\hline Saudi Arabia & Arabs & 410 & $11-18$ & $2.93(1.3-4.56)$ & $\mathrm{N} / \mathrm{A}$ & Osuobeni $^{17}$ \\
\hline Spain & Basques & $174 / 218$ & $15-25$ & $4.02(1.1-6.94)$ & $0.46(0-1.36)$ & \begin{tabular}{|l} 
Rebato \& Cal- \\
deron $^{28}$
\end{tabular} \\
\hline Saudi Arabia & Arabs & $838 / 800$ & $6-19$ & $5.85(4.26-7.44)$ & $0.75(0.15-1.35)$ & $\begin{array}{l}\text { Oriowo \& Alotaibi } \\
\text { (present study) }\end{array}$ \\
\hline
\end{tabular}

Note: The cited surveys employed the Ishihara test (Pseudo-isochromatic plates); $\mathrm{M}=$ males; $\mathrm{F}=$ females; $\mathrm{N}=$ sample size; $\mathrm{CI}=$ confidence interval.

\section{Discussion and Conclusion}

The results of the present investigation show a prevalence of congenital red-green CVD of 5.85\% and $0.75 \%$ among Saudi Arabian male and female children, respectively. The prevalence for females is not significantly different from that found among 10 to 59 year-old Jordanians ${ }^{25}$, but slightly higher than that found among the 18 to 27 year old Jordanian university and Iranian secondary school students ${ }^{19,26}$, Ethiopians ${ }^{27}$, and the Basque population in Spain ${ }^{28}$ (see Table 2). The prevalence for females in the present study is lower than the $3.2 \%$ prevalence found by Al-
Amood et al ${ }^{18}$ among Arab population living in Iraq. The prevalence rates as observed in the present study are within similar range (see Table 2) compared to those found among Pakistanis population living in Quetta $^{29}$, Jordanians ${ }^{19}$, Danish ${ }^{7}$, and Italians ${ }^{30}$. The existence of wide variations in the frequency of inherited defects of colour perception was reported first by Clement ${ }^{31}$.

The results for males in the present study indicate a slightly higher prevalence than those of the two previous reports for central Saudi Arabia, 2.30\% for older male subjects ${ }^{16}$ and $2.93 \%$ for similar school age group of Saudi males ${ }^{17}$ (Table 2). The higher 
prevalence of $5.85 \%$ observed in the present study appears to indicate a gradual increase in the prevalence of CVD among the Saudi male population. Voke and Voke ${ }^{16}$ attributed the observed low prevalence to the fact that Saudi Arabia had until recently been isolated. However, over the past four decades, Saudi Arabia has witnessed a considerable pace of modernisation, thus the increase in the prevalence of red-green CVD in male Saudi Arabians is likely to be due to increasing exogamous marriages, mostly between Saudi males and foreign women or between social classes due to relaxation of a rigid class structure. The effect of urbanisation and industrialisation might not be a factor as the present study dealt with children born to Saudi parents. Further investigation is needed to compare different ethnic groups within Saudi Arabia.

In conclusion, the information on red-green CVD among the female population in Saudi Arabia has been lacking. The present study found the prevalence rate of CVD in Saudi female children to be $0.75 \%$ which is though not significant from, but slightly higher than observed in western populations. As earlier mentioned, Al-Amood et al. ${ }^{18}$ found a prevalence of $3.2 \%$ among female Iraqi Arabs, and explained that this high rate may be due to high frequency of consanguineous marriages, still commonly practised among the Arabs. The reason for using more than 3 errors in the present study was to avoid an under-estimate. In fact, in the analysis of the data in the present study with more than 5 errors which some clinicians use as the pass/fail criterion, the obtained prevalence was $4.2 \%$ and $0.63 \%$, respectively for males and females. Despite that the $4.2 \%$ prevalence (obtained with using more than 5 error criterion) for males is lower than $5.85 \%$ obtained with using more than 3 error criterion, the two values are higher than previously obtained among Saudi males. The result of 5.85\% for the males indicates a higher prevalence than the two previous findings in Saudi Arabia, however not up to that of Caucasian populations. The Ishihara test is designed and commonly used to isolate or screen subjects with slight CVD, while the D15 is designed to grade the degree (and not for CV screening) of CVD. This may explain why in clinical settings some subjects may fail one test and not the other. Another instrument is the anomaloscope which is clinically used for screening and diagnosis of CVD, but its use is beyond the scope of the present study considering the testing duration and its impractical portability to all the study screening sites.

\section{Acknowledgment}

The authors would like to thank all the participants for their cooperation, and Khawater Alqabbani for assisting in data collection.

\section{References}

1. Crognale MA, Teller DY, Yamaguchi T, Motulsky AG, Deeb SS. Analysis of red/green color discrimination in subjects with a single $\mathrm{X}$-linked photopigment gene. Vision Res 199939 707-719.

2. Deeb SS, Kohl S. Genetics of color vision deficiencies. Dev Ophthalmol 200337 170-187.

3. Deeb SS. Molecular genetics of colour vision deficiencies. Clin Exp Optom 200487 224-229.

4. Muller RF, Young ID. Patterns of inheritance. In: Emery's Elements of Medical Genetics 11th ed. Edinburg: Churchill Livingstone, 2001, pp103.

5. Pokorny J, Smith VC, Verriest G. Congenital color defects. In: Eds. Pokorny J, Smith VC, Verriest G, Pinkers AJLG. Congenital and acquired color vision defects. New York: Grune and Stratton, 1979, 183-241.

6. Filosa S, Calabro V, Lania G, Vulliamy TJ, Brancati C, Tagarelli A, Luzzatto L, Martini G. G6PD haplotypes spanning Xq28 from F $8 \mathrm{C}$ to red/green colour vision. Genomics 199317 6-14.

7. Norn M. Prevalence of congenital colour blindness among Inuit in East Greenland. Acta Ophthalmol Scan $1997 \mathbf{7 5}$ 206-209.

8. Motulsky AG. Normal and abnormal color-vision genes. Am J Hum Genet 198842 405-407.

9. Rubin A. Fundamentals of colour awareness: a literature review. S Afr Optom 200564 102-109.

10. Kolb H. How the retina works. American Scientist 200391 28-35.

11. Lee BB. Paths to colour in the retina. Clin Exp Optom 2004 87 239-248.

12. McIntyre D. Colour blindness - Causes and effects. Chester, UK: Dalton Publishing, 2002, pp4-141.

13. Alexander JJ, Umino Y, Everhart D, Chang B, Min SH, Li Q, Timmers AM, Hawes NL, Pang JJ, Barlow RB, Hauswirth WW. Restoration of cone vision in a mouse model of achromatopsia. Nat Med 200713 685-687.

14. Birch J. A practical guide for colour vision examination: a report of the standardization committee of the international research group on colour vision deficiencies. $O p h-$ thal Physiol Opt 19855 265-285.

15. Birch J. Efficiency of the Ishihara test for identifying redgreen colour deficiency. Ophthal Physiol Opt 199717 403408.

16. Voke J, Voke PR. Congenital dyschromatopsia among Saudi Arabians. Saudi Med J 19801 209-214.

17. Osuobeni EP. Prevalence of congenital red-green color vision defects in Arab boys from Riyadh, Saudi Arabia. Ophthal Epidem 19963 167-170. 
18. Al-Amood WS, Mohammed SG, Al Sanawi DAH, Radhi ARH, Abdul Rehman B. Incidence of colour blindness in Iraqi Arabs. Hum Hered 198131 122-123.

19. Al-Aqtum MT, Al-Qawasmeh MH. Prevalence of colour blindness in young Jordanians. Ophthalmologica 2001215 39-42.

20. Post, R. H. Population differences in red and green color vision deficiency: a review and a query on selection relaxa tion. Social Biology 198229 299-315.

21. Ishihara $\mathrm{S}$. The series of plates designed as a test for colordeficiency. 24 plates edition. Tokyo, Japan: Kanehara Trading Inc, 2007.

22. Grosvenor T. The incidence of red-green colour deficiency in New Zealand's Maoris and "Islanders". Am J Optom Arch Am Acad Optom 19706 445-450.

23. Dain SJ, Honson VJ. Selection of an optimal light source for the FM-100 hue test. Doc Ophthalmol Proc Ser 1989 52 425-432.

24. Confidential interval proportion calculation. Dimension Research Inc, Lombard, IL, USA. www.dimensionresearch. com/resources/calculators. Accessed on 15 March, 2008.

25. Al-Salem M, Arafat AF, Hasan Z, Al-Hader AF, Al-Asseer B. Colour vision blindness and discrimination among Jordanians. Saudi Med J 199617 511-515.

26. Modarres M, Mirsamadi M, Peyman GA. Prevalence of congenital color deficiencies in secondary-school students in Tehran. Intern Ophthalmol 199620 221-222.

27. Zein ZA. Gene frequency and type of colour blindness in Ethiopians. Ethiop Med J. 199028 73-75.

28. Rebato E, Calderon R. Incidence of red/green colour blindness in the Basque population. Anthropol Anz 199048 145148.

29. Mian A, Ali M, Rafique S. Frequencies of colour blindness in different ethnic groups of Quetta (Pakistan). Pakistan J Zoology 199123 153-155.

30. Malaspina P, Ciminelli BM, Pelosi E, Santolamazza P, Modiano G, Santillo C, Lofoco G, Talone C, Gatti M, Parisi P. Colour blindness distribution in the male population of Rome. Hum Hered 198636 263-265.

31. Clement F. Racial differences in color blindness. Am J Phys Anthropol 193014417. 